\title{
ANALISIS SUDUT PANDANG KAMERA DAN JENIS KAMERA
}

\author{
Triyono \\ M. Ardy Hariwibowo ${ }^{2}$ \\ Bian Pramana Putra ${ }^{3}$ \\ Dosen STMIK Raharja Tangerang ${ }^{1}$, STMIK Raharja Jurusan Teknik Informatika ${ }^{2,3}$ \\ Jl. Jendral Sudirman No 40 Modern Cikokol Tangerang ${ }^{1,2,3}$

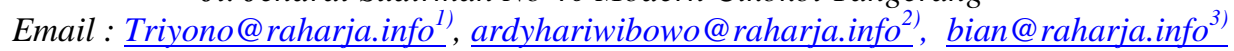

\begin{abstract}
ABSTRAK
Perkembangan teknologi komputer khususnya bidang multimedia, audio visual dan broadcasting sudah sangat berkembang pesat saat ini serta semakin luasnya kebutuhan akan informasi pada masyarakat, maka semakin banyak kontribusi baru dalam menyajikan pengambilan gambar, Kamera adalah alat paling populer dalam aktivitas fotografi. Nama ini didapat dari camera obscura, bahasa Latin untuk "ruang gelap", mekanisme awal untuk memproyeksikan tampilan di mana suatu ruangan berfungsi seperti cara kerja kamera fotografis yang modern, kecuali tidak ada cara pada waktu itu untuk mencatat tampilan gambarnya selain secara manual mengikuti jejaknya. Dalam dunia fotografi, kamera merupakan suatu peranti untuk membentuk dan merekam suatu bayangan potret pada lembaran film. Pada kamera televisi, sistem lensa membentuk gambar pada sebuah lempeng yang peka cahaya. Lempeng ini akan memancarkan elektron ke lempeng sasaran bila terkena cahaya. Selanjutnya, pancaran elektron itu diperlakukan secara elektronik. Dalam dunia fotografi tidak sedikit fotografer apalagi yang masih pemula, seolah terlena pada hal-hal yang bersifat teknis saja, seperti mengatur bukaan diafragma, pengaturan kecepatan, dan pengaturan jarak. Mungkin juga, selama ini tidak terpikirkan bahwa di dalam foto itu terkandung nilai-nilai tertentu yang dapat membuat foto itu bagus atau sebaliknya menjadi berantakan. Salah satunya adalah pengaturan komposisi. Mungkin belum pernah membayangkan, bahwa dengan pengaturan komposisi sesungguhnya dapat ditonjolkan subjek utama. Bahkan tidak jarang akan mendukung keberhasilan foto-foto yang kita buat. ebuah alat inti dalam fotografi bernama camera juga mempunyai jenis yang berbeda dengan masingmasing kegunaanya. Dengan berkembangnya teknologi, masyarakat dapat mencari infomasi menggunakan telepon genggam sehingga mampu diakses kapan saja dan dimana saja.
\end{abstract}

Kata kunci: fotografi, Kamera, camera

\section{ABSTRACT}

The development of computer technology in particular fields of multimedia, visual and audio broadcasting already very rapidly growing at this time as well as the extent of the need for information on the society, the more recent contributions in presenting the image capture, the camera is the most popular tool in photography. The name is derived from the camera obscura, Latin for "dark room", an early mechanism for projecting a display where an indoor function like the workings of a modern photographic camera, except there is no way at this time to take down the display of the drawing in addition to manually follow in his footsteps. In the world of photography, a camera is a device to establish and record a shadow portraits on sheet film. At the television cameras, the system of lenses to form an image on a light sensitive plate. This plate will emit electrons into the target plate when exposed to light. Furthermore, a steady stream of electrons that are treated electronically. In the world of photography does little photographers especially that still seems to be beginners, on things that are technical, such as regulating the aperture diaphragm setting, pace, and distance settings. It's also possible, as long as it is not unthinkable that in the picture contained certain values that can make photos that are good or otherwise become a mess. One of them is setting the composition. May have never imagined, that by setting the actual composition can be highlighted the main subject. Not even rarely will support the success of the photos that we make. a core tool in photography called camera also has different types with masingmasing kegunaanya. With the development of technology, 
people can search for information using a cell phone so that it is able to be accessed anytime and anywhere.

Keywords: photography, camera, camera

\section{PENDAHULUAN}

Alat perangkat kamera yang digunakan untuk mengambil gambar bergerak dan menyimpannya di media tertentu, yang selanjutnya dilakukan proses pengolahan dari mode gambar analog menjadi gambar digital.

Ada beberapa jenis handycam bisa digunakan untuk kualitas broadcast, seperti Sony seri DSR DVCam dan Canon XL-1 Ada beberapa jenis pita video yang dikenal dan sering kali digunakan oleh film maker pemula yaitu VHS/Super VHS, Betamax, Video 8/Hi 8.Seiring dengan pesatnya perkembangan teknologi, kini muncul produksi jenis Mini DV (digital video) dan digital 8 yang sistem perekamannya tidak analog lagi melainkan dengan sistem digital.

Dalam hal perawatan yang perlu diperhatikan terkait bahan baku pita video adalah harus disimpan di tempat yang kering, bersih, dan sejuk sebab sedikit debu saja akan mengakibatkan robeknya (scratch) gambar dilayar. Kerentanan lainnya pada pita video, yaitu kelembaban yang mengakibatkan jamur dan suhu panas akan mengubah bentuk pipa serta sedikit cacat pada pita akan merusak video head yang berputar pada sistem perekaman pita video (VTR atau Video Tape Recorder).

Body kamera sangat berperan penting, selain untuk melindungi sistem didalamnya body juga berfungsi sebagai kamar gelap yang dapat membantu menangkap image gambar dari obyek yang terkena cahaya Pada body kamera video terdapat sensor yang dapat mengubah gelombang cahaya menjadi bentuk gelombang elektromagnetik berupa sinyal video. Sensor tersebut berwujud chip elektronik yang biasa disebut CCD (charge couple device), karena CCD inilah image gambar bisa direkam dengan alat video tape recorder

\section{LANDASAN TEORI}

Perkembangan Kamera Video Pada perkembangannya kamera telah mengalami langkah-langkah penyempurnaan sebagai suatu piranti dalam produksi karya audio visual, dimana dahulu perangkat tersebut hanya identik dengan spesifikasi keilmuan dari bidang tata fotografi, akan tetapi kini hampir setiap orang bisa menggunakan kamera.

"Camera/kamera adalah piranti dengan perlengkapan lensa yang secara optik mekanik/optik elektronik merekam gerakan suatu obyek yang dijadikan sasaran, berasal dari bahasa latin "Camera" atau bahasa Yunani "Kamera" yang berarti "lompatan".

\section{PERMASALAHAN}

Kamera profesional broadcast dipakai oleh seseorang yang profesional dibidangnya, sebab penggunaannya memerlukan beragam keterampilan dan pengetahuan khusus tentang fasilitas kamera. Kamera handycam disebut juga kamera keluarga karena lebih banyak digunakan demi kepentingan keluarga dan pengoperasiannya lebih mudah. 


\section{SUDUT PANDANG KAMERA}

Sebuah gambar memuat sebuah cerita, cerita memerlukan pemaparan. Gambargambar ada dalam film, merupakan gambar yang telah dipilih, dicari dan di perhitungkan segala kemungkinan ruang seni yang diciptakan, seperti shot yang baik adalah satu bagian dari rangkaian gambar yang begitu panjang, yang hanya direkam dengan satu take saja. Shot yang baik adalah kombinasi sebagai komposisi gambar kedalam satu kali pengambilan gambar. Untuk itu penting mengetahui makna dari sebuah shot. Dalam film, gambar tidak bisa diambil seenaknya sendiri tanpa konsep yang jelas, karena dapat membingungkan penonton.

\section{LITERATURE REVIEW}

1. Jurnal Perancangan Sistem Motion Kamera Pengawas Menggunakan Webcam dan Motor Stepper Berbasis Client - Server, Muhamad Deky Akbar, Prajna Deshanta Ibnugraha, Mohamad Idham Iskandar, penulis menjelaskan menggunakan kamera pengawas dengan menggunakan webcam dan motor Stepper Berbasis Client, Universitas Telkom 2012 ${ }^{[7]}$.

2. Aplikasi Pengamatan Bawah Laut Menggunakan Kamera Webcam. Rizky Maulana, Rozeff Pramana, ST, MT, Deny Nusyirwan, ST, M.Sc. penulis menjelaskan tentang pengamatan bawah laut dengan menggunakan kamera webcam. Universitas Maritim Raja Ali Haji $2013^{[8]}$.

3. Kalibrasi Parameter Kamera Dengan Menggunakan Projector Untuk Rekonstruksi 3d Berbasis Etode Structured Light. R Dimas Adityo. Menjelaskan tentang menggunakan projektor untuk rekonstruksi 3D berbasis Etode Universitas Maritim Raja Ali Haji $2013^{[2]}$.

\section{PEMECAHAN MASALAH}

Dalam kamera video agar gambar yang kita hasilkan memiliki nilai dan terkesan indah harus diperhatikan mengenai masalah penggunaan sudut pengambilan gambar yang baik, yaitu:

\section{TEKNIK PENGAMBILAN GAMBAR}

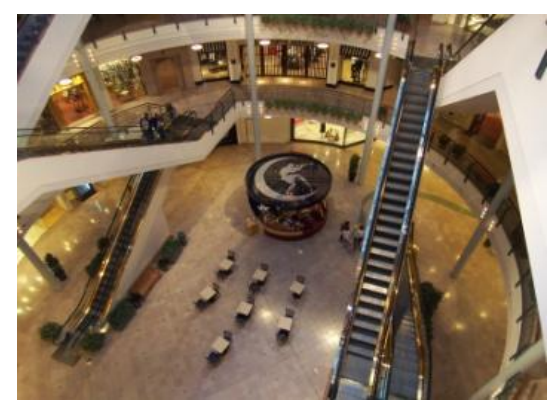

Gambar 1. Gambar ketinggian dengan kamera berada di atas obyek yang terekam

$$
\begin{aligned}
& \text { Bird eye view } \\
& \text { Teknik pengambilan gambar yang } \\
& \text { dilakukan kamerawan dari ketinggian } \\
& \text { dengan kamera berada di atas obyek yang } \\
& \text { terekam. }
\end{aligned}
$$




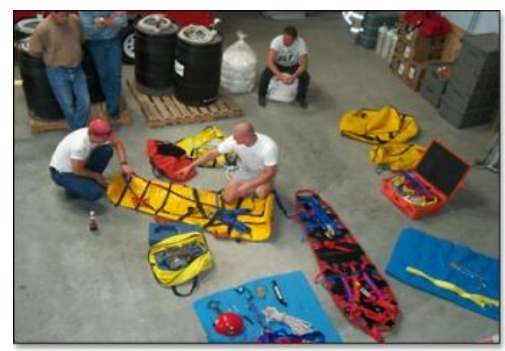

Gambar 2. gambar dari atas obyek dengan kesan obyek jadimengecil

High angle

Sudut pengambilan gambar dari atas obyek dengan kesan obyek jadi mengecil, selain

itu teknik ini menghasilkan kesan dramatis, yaitu nilai "kerdil".

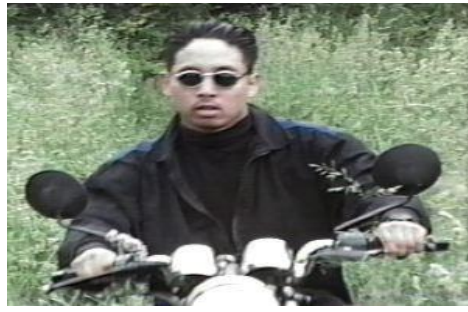

Gambar 3. gambar yang sejajar dengan obyek

\section{Eye level}

Sudut pengambilan gambar yang sejajar dengan obyek, dalam berita sudut seperti ini banyak digunakan karena menghasilkan kesan sama rata atau sejajar. Hasilnya memperlihatkan tangkapan pandangan mata seseorang yang mempunyai ketinggian tubuh tepat tingginya sama dengan obyek.

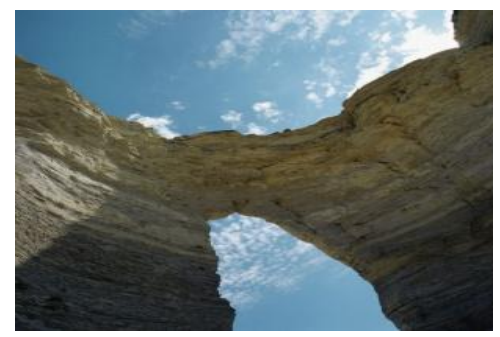

Gambar 4. pengambilan dari arah bawah obyek sehingga kesan obyek menjadi besar

\section{Low angle}

Sudut pengambilan dari arah bawah obyek sehingga kesan obyek menjadi besar dan tinggi, hal ini bersifat dramatisir,yaitu keagungan

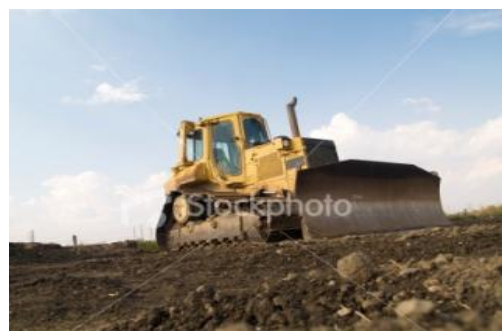

Gambar 5. gambar dengan ketinggian kamera sejajar dengan tanah ( dasar obyek ). 


\section{Frog eye}

Teknik pengambilan gambar dengan ketinggian

kamera sejajar dengan tanah ( dasar obyek ).

Sudut seperti ini hampir tidak pernah ditemui

dalam peliputan berita, karena memberikan

kesan bahwa obyek menjadi sangat besar.

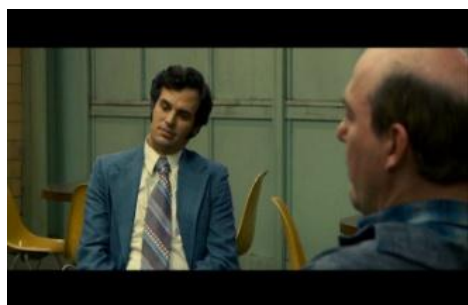

Gambar 6. dialog dari sudut belakang/ panggung bahu salah satu subyek

Over shoulder

Mengambil adegan dialog dari sudut belakang/ panggung bahu salah satu subyek sinematik. ( prominence ).

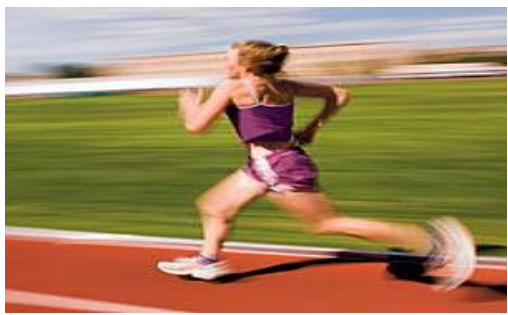

Gambar 7. Wallking shot adalah follow shot yakni mengikuti obyek,

\section{Walking shot}

Wallking shot adalah follow shot yakni mengikuti obyek,

\section{TYPE OF SHOT}

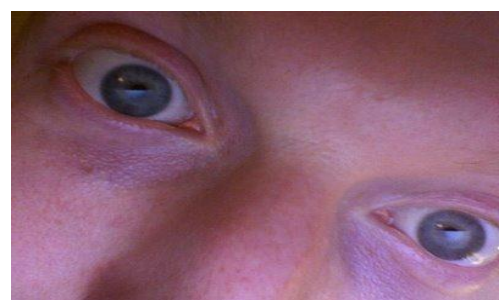

Gambar 8. gambar yang sangat dekat sekali

\section{Extreme close up ( ECU )}

pengambilan gambar yang sangat dekat sekali, fungsinya untuk memperlihatkan detail suatu obyek secara jelas.

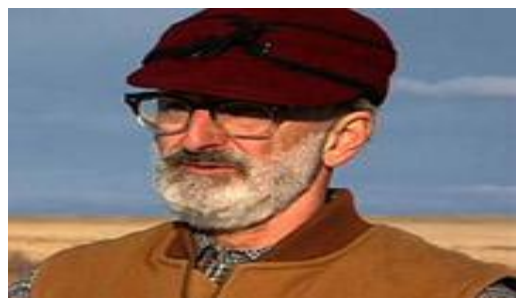

Gambar 9. gambar pas dari atas kepala sampai bawah leher 


\section{lose up ( $\mathrm{CU}$ )}

Pengambilan gambar pas dari atas kepala sampai bawah leher, fungsinya memberikan gambaran obyek secara jelas.

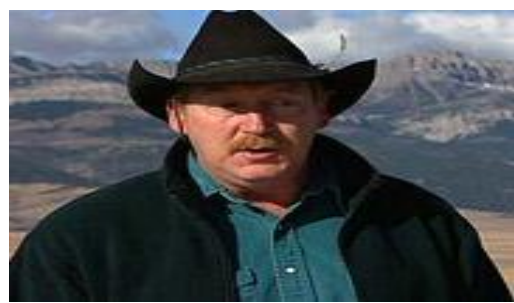

Gambar 10. gambar dari atas kepala sampai dada

\section{Medium close up ( MCU )}

Pengambilan gambar dari atas kepala sampai dada, fungsinya menegaskan "profil" seseorang agar penonton melihat dengan jelas.

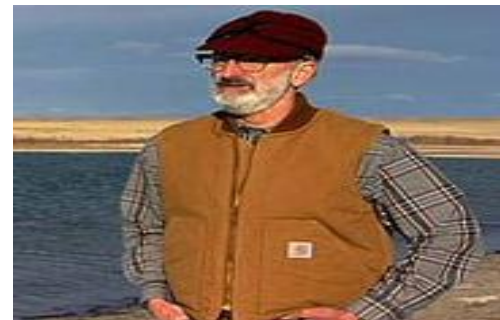

Gambar 11. gambar sebatas kepala sampai pinggang

Medium shot ( MS )

Ukuran gambar sebatas kepala sampai pinggang fungsinya memperlihatkan sosok seseorang dengan karakternya

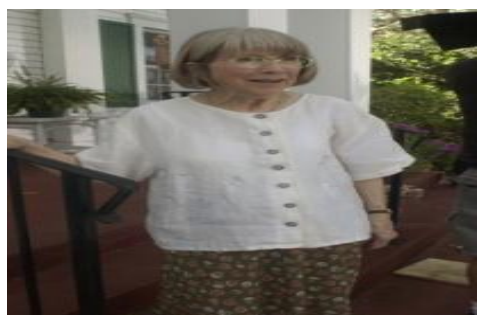

Gambar 12. gambar yang sangat dekat sekali

\section{Knee shot ( KS )}

Pengambilan gambar sebatas kepala hingga lutut, fungsinya sama dengan MS, yakni mempertegas karakter seseorang.

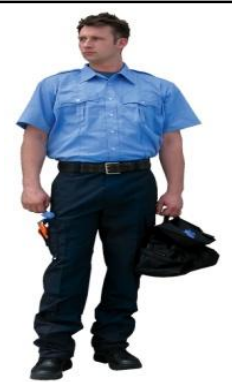

Gambar 13. gambar penuh dari atas kepala hinga kaki 


\section{Full shot (FS)}

Pengambilan gambar penuh dari atas kepala hinga kaki, fungsinya memperlihatkan obyek dengan lingkungannya

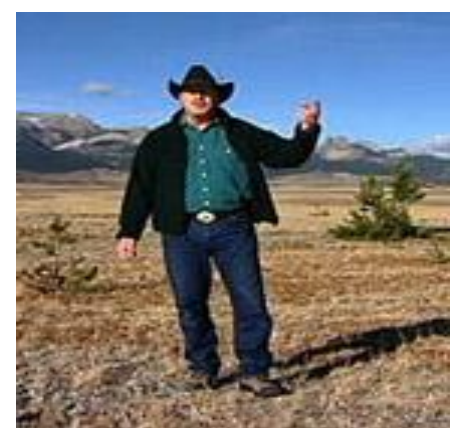

Gambar 14. Pengambilan gambar melebihi FS

\section{Long shot ( LS )}

Pengambilan gambar melebihi FS, fungsinya menunjukkan obyek dengan latar belakangnya

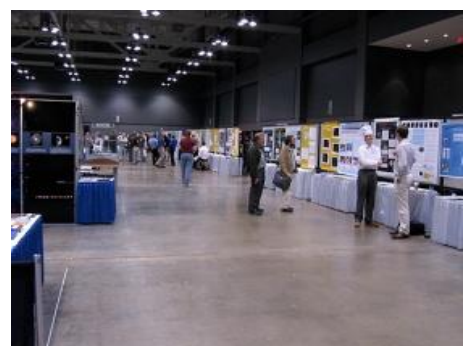

Gambar 15. Pengambilan gambar dimana obyek tampak berada dikejauhan

Ekstreme long shot ( ELS )

Pengambilan gambar dimana obyek tampak berada dikejauhan, berguna untuk mempertegas dan membantu imajinasi ruang cerita dan peristiwa kepada penonton

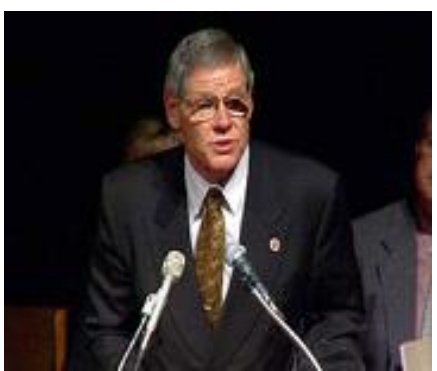

Gambar 16. didalam frame terdapat satu orang

\section{One shot}

Apabila didalam frame terdapat satu orang / obyek. 


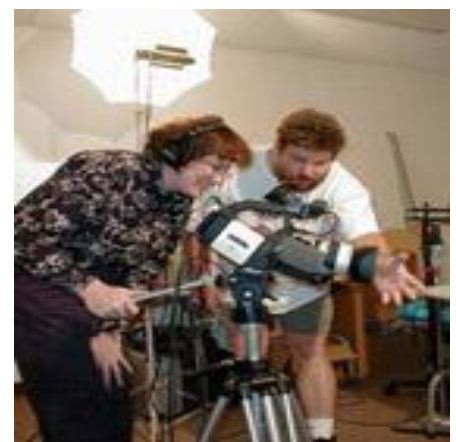

Gambar 17. gambar dalam satu frame terdapat dua obyek

Two shot
Pengambilan gambar dalam satu frame terdapat
dua obyek

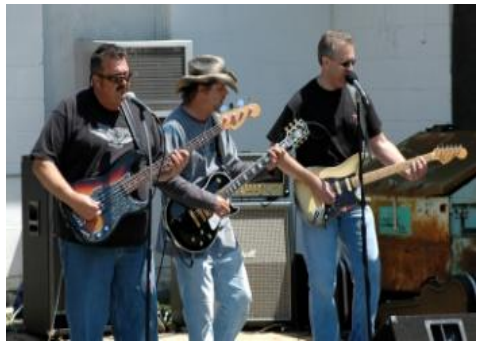

Gambar 18. gambar dari tiga orang obyek dalam satu frame.

\section{Three shot \\ Pengambilan gambar dari tiga orang obyek dalam satu frame.}

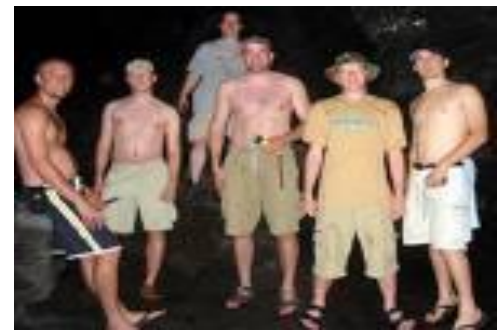

Gambar 19. pengambilan gambar dengan memperlihatkan obyek lebih dari tiga orang.

\section{Group shot}

teknik pengambilan gambar dengan

memperlihatkan obyek lebih dari tiga orang.

\section{PERGERAKAN KAMERA ( CAMERA MOVEMENT )}

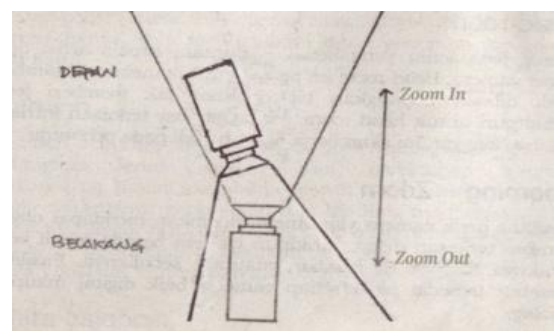

Gambar 20. pengambilan gambar obyek tanpa harus mendekati obyek. 


\section{Zoom in - zoom out}

pengambilan gambar obyek tanpa harus mendekati obyek ( zoom in ) atau menjauhi obyek ( zoom ou t). Pada pengambilan gambar zoom, kamera tidak bergerak tapi hanya menekan tombol zooming.

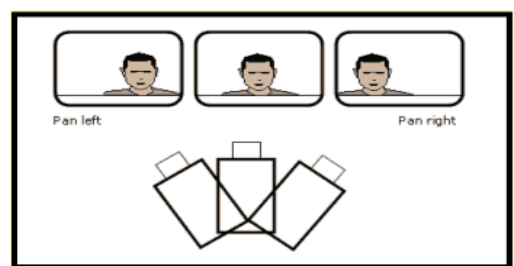

Gambar 21. gambar secara mendatar ( horizontal ).

Panning
Pengambilan gambar secara mendatar (
horizontal ) secara berurut dan halus. Pada
gerakan panning, posisi kamera tidak berubah
yang bergerak adalah handle pada tripod
penyangga karena yang digerakkan ke kanan
(pan right) atau ke kiri (pan left).

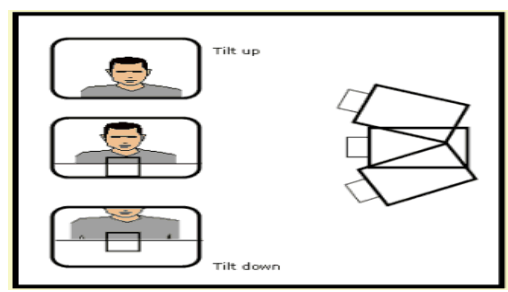

Gambar 22. gambar dari bawah ke atas ( tilt up ) atau dari atas ke bawah ( tilt down ).

\section{Tilting}

Pengambilan gambar dari bawah ke atas ( tilt up ) atau dari atas ke bawah ( tilt down ). Untuk mendapatkan gerakan yang halus, kamera sebaiknya berada di atas tripod dan yang digerakan adalah handle pada tripod.

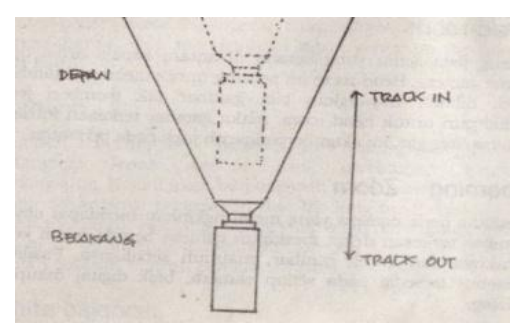

Gambar 23. gambar dengan menggunakan tripod dan dolly

\section{Tracking}

Pengambilan gambar dengan menggunakan tripod dan dolly sebagai dudukan tripod sehingga kamera dapat digerakkan ke depan mendekati obyek (track in) atau kebelakang menjadi obyek ( track out). 


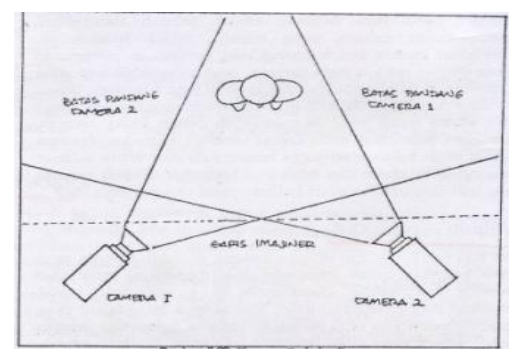

Gambar 24. Garis khayal pengambilan gambar sebagai batas gerak pandang kamera

\section{Garis imajiner}

Garis khayal pengambilan gambar sebagai batas gerak pandang kamera untuk menjaga konsitensi posisi objek antar frame. Jika ini dilanggar maka sangat mungkin bila penonton akan menjadi binggung, karena pengambilan gambar dilakukan dari reverse angle.

\section{KAMERA STUDIO}

Kamera studio adalah kamera yang biasanya digunakan dalam studio (indoor) untuk memproduksi sebuah program acara televisi.

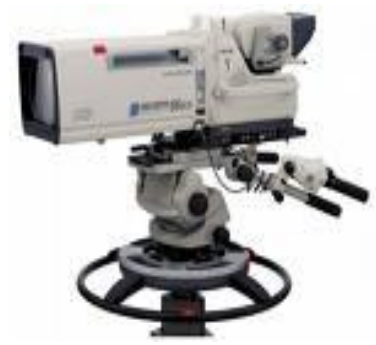

Gambar 25. Kamera Pocket

\section{KAMERA EFP (Electronic Field Production)}

Kamera EFP biasanya digunakan oleh stasiun-staisun maupun rumah produksi untuk produksi dalam ruangan (indoor), hampir sama dengan jenis yang pertama.

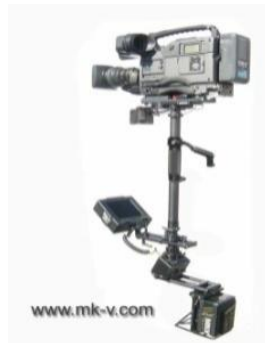

Gambar 26. Kamera EFP

\section{KAMERA FILM ELEKTRONIK}

Kamera film elektronik merupakan hasil kemajuan yang bidang kerjanya sudah serba elektris. Hasil perekaman gambarnya sangat cepat, selesai melakuakn perekaman, saat itu pula hasilnya dapat dilihat dan dinikmati. 


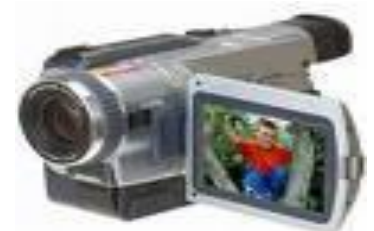

\section{KAMERA FILM KHUSUS}

Gambar 27. Kamera Film Elektronik

Kamera film khusus ini dibentuk dan dibuat secara khusus karena adanya suatu tuntutan yang mendesak, terutama yang atau pada saat kamera jenis lainnya tidak mampu. Seperti underwater camera ( kamera bawah air ).

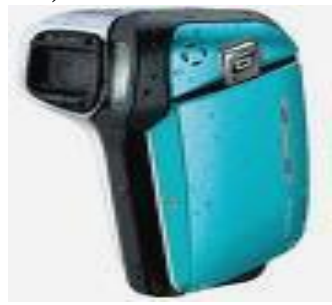

Gambar 28. Kamera Film Khusus

\section{HANDYCAM ATAU KAMERA VIDEO 8}

Kamera jenis ini tergolong analog, nama video 8 diambil dari ukuran pita kaset sebagai bahan untuk perekaman gambar berukuran $8 \mathrm{~mm}$. Konsumsi kamera jenis ini biasa digunakan untuk kebutuhan rumahan, bentuknya kecil, ringan, ramping dan pas di tangan. Kualitas gambarnya setara VCD yang mempunyai frame size ( ukuran frame ) 320 pixel x 240 pixel dan dijuluki kamera consumer atau kamera publik. Perusahaan elektronik yang memproduksi dalam beberapa tipe adalah Sony, namun merek lain seperti Panasonic, JVC, Samsung, Philips dan Sanyo.

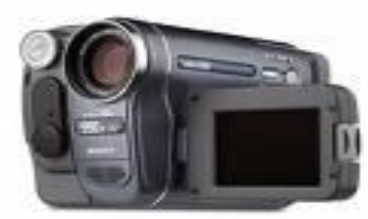

\section{KAMERA VHS ATAU VIDEO 16}

Gambar 29. Handycam atau kamera video 8

Kamera jenis ini termasuk kamera professional berformat analog. Di era 90-an kamera ini menjadi andalan para jurnalis televisi, dari bentuknya yang besar, kokoh, dan lensa yang dapat diganti-ganti sesuai kebutuhan. Bahan kaset atau tipe kasetnya berformat VHS, kamera jenis ini merupakan standar bagi penyiaran televisi dan untuk media preview - nya menggunakan video player VHS, kualitas gambarnya pun lebih tinggi dibanding handycam yaitu 400 garis TV.

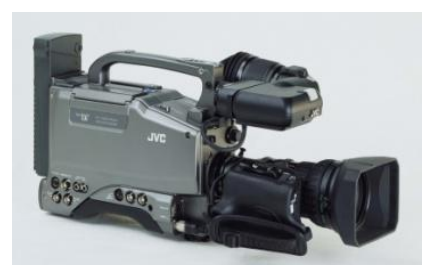

Gambar 30. Kamera VHS atau Video 16 


\section{KAMERA MINI DV}

Kamera jenis ini tergolong format digital, beberapa dari kamera yang mulanya berformat handycam dan beresolusi rendah banyak diubah menjadi format Mini DV. Seperti pada produk Sony dengan meningkatkan resolusi menjadi 900 pixel bahkan ada yang mencapai 3000 pixel. Canon CL - Z telah memperbaiki kualitas gambarnya menjadi megapixel dengan dilengkapi lensa berkualitas dan teknologi $3 C C D$.

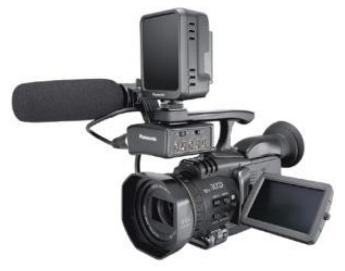

Gambar 31. Kamera Mini DV

\section{KAMERA DV}

Kamera ini berformat digital, selain itu tergolong kamera professional yang digunakan standar broadcast. Resolusinya 600 garis TV dengan bitrate 25 Mbps dan kompresi video 5:1, yang tergolong dalam jenis ini adalah keluaran Panasonic AG EZ 30 3CCD dan AG EZI 3CCD.

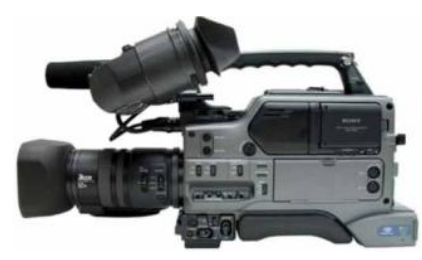

Gambar 32. Kamera DV

\section{KAMERA DV CAM / DVC PRO}

Kamera format digital dengan spesifikasi lebih tinggi dari kamera DV. Nama kamera DV Cam dan kamera DVC Pro perbedaannya adalah masalah nama dari pabrikan. Sony menggunakan nama DVCam, sedangkan Panasonic menggunakan DVC Pro. Resolusi mencapai 800 - 900 garis TV dengan bit rate lebih tinggi dari DV. Kamera ini merupakan kamera kualitas tinggi dipakai standard industri penyiaran. Banyak karya-karya produk Audio Visual untuk konsumsi acara Televisi misalnya video clip, sinetron dan pemberitaan menggunakan kamera jenis ini. Yang tergolong kamera jenis ini adalah keluaran Panasonic diantaranya AJ D410 A dan AJ D610 WB, sedangkan Sony mengeluarkan DSR 400 WSP dan DSR 300 P.

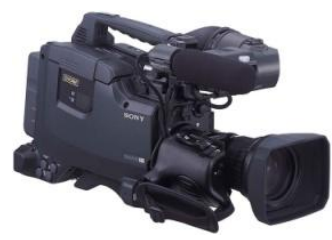

Gambar 33. Kamera DV Cam 


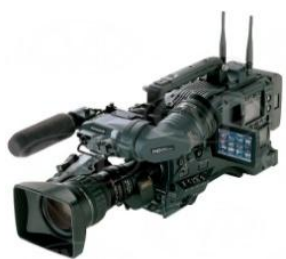

Gambar 34. Kamera DVC Pro

\section{KAMERA BETACAM SP}

Kamera Betacam SP merupakan kamera pertama Sony untuk format Betacam. Kamera ini diperkenalkan pertama kali pada tahun 1980, dimana kamera ini mepunyai resolusi mencpaai 600 garis TV dan bit reat 25 Mbps. Kemudian pada tahun 1993 kamera Betacam dikembangkan menjadi format digital dengan meningkatkan resolusi 800 - 900 garis TV dengan kompresi video 5 : 1. yang tergolong jenis kamera ini adalah keluaran Sony diantaranya DNW 90 WSP dan DNW 9 WSP.

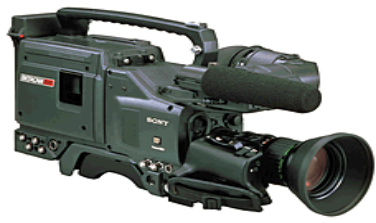

Gambar 35. Kamera Betacam SP

\section{KAMERA BETACAM HIGH DEFINITION TV (HDTV)}

Kamera jenis ini adalah format digital terbaru dengan kualitas gambar yang tinggi mempunyai resolusi gambar 1080 garis TV yang dilengkapi dengan progressive scaned. Sedangkan bit rate yang dihasilkan adalah 1,2 Gbsps. Kamera ini adalah tekhnologi terbaru dengan konsumsi televisi plasma atau televisi seri HD ( high definition ). Yang tergolong kamera jenis ini adalah HDW 750P dan HdW F900 keluran dari Sony.

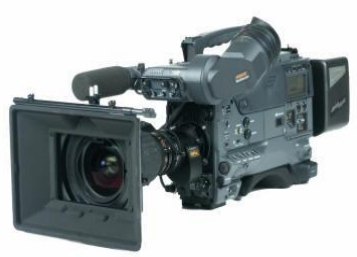

Gambar 37. Kamera Betacam High Definition TV

\section{KAMERA MOBIL (CAMERA CAR)}

Kamera jenis ini adalah format digital terbaru dengan kualitas gambar yang tinggi. Yang cara penggunaannya semua crew dan sutradara melakukannya diatas mobil dan kamera pun menggunakan jimmy jib agar bisa bergerak ke segala arah.

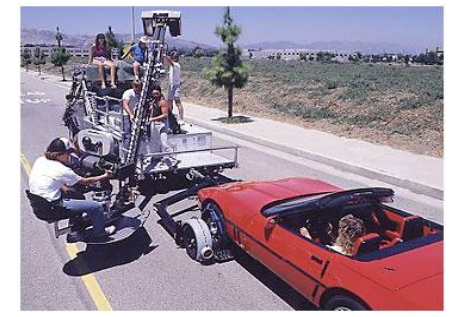

Gambar 38. Kamera mobil (Camera Car) 


\section{KAMERA HIGH DEFINATION}

Kamera tersebut format digital terbaru dengan kualitas gambar yang tinggi. Kamera ini teknologi terbaru dengan konsumsi televisi plasma atau seri $\mathrm{HD}$ (High Defination), yang tergolong jenis kamera ini HDW 750P dan HDW F900 Keluaran Sony.

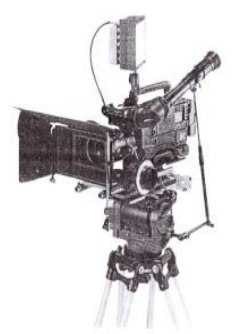

Gambar 39. Kamera High Defination

\section{KOGAN 12MP ACTION CAMERA 1080P}

Dengan kamera 12MP dan resolusi video 1080p, Kamera Kogan action camera ini akan menghasilkan gambar sangat jernih. Layar sentuh yang dimiliki oleh kamera ini, akan membantu Anda untuk melihat hasil foto atau video secara lebih jelas. Dengan memory internal yang mencapai hingga 64GB, Anda dapat mengabadikan banyak momen dalam hidup Anda. Kamera ini juga dapat digunakan hingga 30 Meter dibawah air.

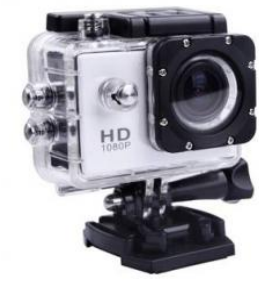

Gambar 40. Kamera Kogan 12MP Action Camera 1080p

\section{KLASIFIKASI WHITE BALANCE}

ada satu hal penting yang perlu diketahui seorang kamera operator yaitu White Balance. White Balance adalah sebuah standarisasi warna akibat cahaya yang mausk. White balance ini diperlukan karena ada kemungkinan perbedaan pewarnaan penangkapan cahaya pada kamera saat pengambilan gambar dilakukan didalam ruangan maupun di luar ruangan. Untuk mendapatkan white balance ini menggunakan kertas HVS warna putih yang diletakkan di lensa kamera kemudian difokuskan pada kertas tersebut. Gunakan fasilitas tombol white balance sehingga lampu indikator white balance menunjukkan stabil dan tidak lagi berkedip $^{[4]}$.

\section{BAGIAN DARI KAMERA VIDEO}

Pada dasarnya kamera video terdiri atas tiga bagian, diantaranya :

\section{LENSA}

Lensa mempunyai fungsi menangkap obyek secara optik yang menghasilkan gambar dan diteruskan ke permukaan tabung kamera (oleh tabung kamera diubah lagi dari optik ke 
elektrik). Jenis lensa dibedakan menurut panjang fokalnya (jarak antara pusat optik lensa dengan suatu titik saat gambar terlihat dalam keadaan fokus ${ }^{[5]}$.

Jenis-jenis lensa :

a. Lensa Normal

Lensa normal / lensa standart, gambar yang dihasilkan memberi kesan yang biasa dan datar tidak ada efek distorsi ataupun melengkuk. Lensa normal berukuran fokus sepanjang $50 \mathrm{~mm}$ atau $55 \mathrm{~mm}$, sudut pandang ini sama dengan sudut pandang mata manusia.

b. Lensa Wide atau Sudut Lebar

Jangkauan dari subyek yang bisa ditangkap oleh lensa wide cukup lebar, dengan menggunakan lensa wide kameraman tidak perlu mundur guna mengambil jarak karena ada beberapa bagian yang tidak tertangkap lensa. Pada umumnya lensa lebar mempunyai lebar fokus $16-24 \mathrm{~mm}$.

c. Lensa Tele

Lensa tele adalah lensa dengan focal length yang panjang, lensa ini digunakan untuk memperoleh ruang tajam yang pendek dan dapat menghasilkan perspektif wajah yang mendekati aslinya. Lensa tele berukuran $85 \mathrm{~mm}, 135 \mathrm{~mm}, 200 \mathrm{~mm}$.

d. Lensa Macro

Lensa ini sangat baik digunakan untuk merekam benda-benda kecil, seperti serangga. Panjang fokal lensa macro sekitar 55mm-105mm.

e. Lensa Vario atau Zoom

Lensa jenis ini merupakan penggabungan dari lensa sudut lebar dan lensa tele, cukup satu lensa sudah mencakup semua jenis lensa, yakni lesa normal, wide, tele, dan macro.

\section{BODY KAMERA}

Body kamera berisi tabung pengambil gambar (pick up tube) yang berfungsi mengubah gambar optik yang dihasilkan lensa menjadi sinyal elektrik. Body kamera dilengkapi dengan beberapafasilitas kamera seperti : white balance, steady shot, digital effect, shutter speed, dll ${ }^{[1]}$.

\section{VCR (Video Cassette Recorder)}

VCR adalah alat perekam gambar dan suara. Pada beberapa kamera ada yang recordnya terpisah seperti jenis U-matic, tetapi ada juga yang menjadi satu dengan body kamera sehingga menjadi lebih ringan, efisiensi waktu, dan pekerjaan menjadi lebih mudah ${ }^{[3]}$.

\section{CARA MERAWAT KAMERA VIDEO}

1. Jangan tinggalkan kaset didalam camcorder saat tidak digunakan

2. Jangan memasukkan kaset video dalam kondisi benar-benar dingin

3. Jangan meninggalkan baterai didalam camcorder saat tidak digunakan

4. Jangan meninggalkan kaset camcorder didalam mobil yang terkena udara panas

5. Rawatlah kamera video dengan cara menyerahkan kepada teknisi untuk membersihkan tape head saat kotor. 


\section{SINGLE DAN MULTI CAMERA PRODUCTION}

Shooting dengan single camera biasa dilakukan di luar ruangan (out door) dengan hanya menggunakan satu kamera, tripot, dan microphone.

Shooting dengan multi camera lebih banyak dilakukan saat pengambilan gambar video di studio (in door) dengan menggunakan dua kamera atau lebih, switcher, CCU (camera control unit), VTR, waveform, lighting, telepromter, microphone, dan peralatan lainnya.

Switcher adalah suatu alat yang berfungsi memindahkan atau menggantikan pemilihan gambar dari berbagai stock shot maupun input kamera

CCU (camera control unit) merupakan peralatan yang berhubungan dengan fungsi dari sebagian atau keseluruhan kamera, fungsinya untuk mengatur keseimbangan warna, memonitor dan mengatur parameter teknik secara keseluruhan, serta mengirim tanda ke operator kamera.

VTR adalah peralatan yang berguna untuk merekam atau memutar gambar yang dihasilkan kamera $^{[6]}$.

\section{MEREKAM VIDEO SECARA SEMPURNA}

Ada beberapa cara yang penting untuk diketahui seorang kameraman agar video yang dihasilkan bernila sempurna, beberapa pertimbangan yang penting saat merekam video :

1. Jika memungkinkan gunakan selalu manual fokus

2. Aturlah white balance pada setiap perpindahan lokasi atau pergantian sumber cahaya

3. Jika melakukan pengambilan gambar diluar ruangan posisikan matahari dibelakang kita agar tidak melawan cahaya

4. Gunakan tripot atau alat bantu lainnya

5. Pegang dan kendalikan kamera video sedemikian rupa agar hasil rekaman tetap stabil

6. Gunakan zooming hanya untuk menata komposisi pengambilan gambar

7. Pastikan untuk memperoses lebih lanjut setiap hasil rekaman

8. Jagalah durasi setiap shoot, jangan terlalu panjang dan monoton

9. Jagalah setiap shot dalam kondisi diam tanpa pergerakan kamera minimal selama 10 (sepuluh) detik

10. Mulailah mengatur komposisi antar obyek bidikan sehingga berada dalam satu frame

11. Sangat penting untuk menempatkan obyek bidikan berada dalam posisi yang nyaman dilihat didalam sebuah frame

12. Selain teknik video tersebut, kita juga harus memperhatikan masalah audio

\section{CARA UNTUK MEMAKSIMALKAN PENGOPERASIAN KAMERA VIDEO}

Teknik dasar pengoperasian kamera sebenarnya hampir sama dengan dengan cara merekam video secara sempurna, beberapa teknik yang harus diperhatikan :

1. Jangan sering menggunakan Zoom

2. Jangan melawan sumber cahaya

3. Pengaturan lighting

4. Durasi merekam yang tepat

5. Ikuti pergerakan obyek

6. Usahakan memakai tripot

7. Kenali perangkat kamera

8. Jangan pergunakan efek pada kamera 


\section{KESIMPULAN}

Penulis berkesimpulan bahwa Sudut pandang kamera dan jenis kamera sangat di perlukan oleh masyarakat luas, sehingga dapat meningkatkan suatu ilmu yang di dapat pada saat masyarakat menggunakan kamera video Sebelum kamera ditemukan, orang membuat gambar dengan melukis atau menggambar. Itu membutuhkan waktu dan bisa tidak akurat. Ditemukannya kamera obskura merupakan tonggak perubahan adanya kamera yang kita manfaatkan saat ini. Kamera memungkinkan orang untuk membuat catatan visual dari kehidupan mereka dan kejadian penting. Tiba-tiba orang bisa melihat foto-foto suatu tempat yang jauh. Kamera membawa seluruh dunia menjadi lebih dekat dan terbayangkan. Foto-foto mulai mempengaruhi orang-orang dan berpendapat tentang dunia. Kamera membawa perubahan besar pada kehidupan.

\section{DAFTAR PUSTAKA}

[1] Abdul Razaq. 2011. The Magic of Movie Editing. Medika Kita. Jakarta

[2] Adityo Dimas R. 2013. Kalibrasi Parameter Kamera Dengan Menggunakan Projector Untuk Rekonstruksi 3d Berbasis Etode Structured Light. Menjelaskan tentang menggunakan projektor untuk rekonstruksi 3D berbasis Etode Universitas Maritim Raja Ali Haji.

[3] Andi. 2011. Pengolahan Video Digital. Wahana Komputer. Jakarta.

[4] Andi Fachruddin. 2011. Dasar-dasar Produksi Televisi, Kencana, Jakarta.

[5] Eva Arifin, 2011. Broadcasting To Be Broadcaster

[6] Hendratman, Hendi. 2012. The magic of Adobe Premier Pro. Informatika Bandung.

[7] Indah Rahmawati. 2011. Berkarir di Dunia Broadcast, Laskar Aksara, Jakarta.

[8] Tino Saroengallo. 2011. Dongeng sebuah produksi film, Kompas Gramedia. Jakarta.

[9] Akbar Deky Muhamad. Ibnugraha Prajna Deshanta Iskandar Mohamad Idham Jurnal Perancangan Sistem Motion Kamera Pengawas Menggunakan Webcam dan Motor Stepper Berbasis Client - Server, 2012. penulis menjelaskan menggunakan kamera pengawas dengan menggunakan webcam dan motor Stepper Berbasis Client, Universitas Telkom.

[10] Pramana Rozeff ST, MT, ST, M.Sc. Maulana Rizky. 2013. Aplikasi Pengamatan Bawah Laut Menggunakan Kamera Webcam. penulis menjelaskan tentang pengamatan bawah laut dengan menggunakan kamera webcam. Universitas Maritim Raja Ali Haji. 